\title{
El arco y la flecha: reactivación y puesta en valor de la artesanía rama
}

\author{
Steve Hayes \\ Francisco Montalván
}

El pueblo indígena rama se destaca en la construcción y utilización del arco y la flecha. Este pueblo se localiza en forma exclusiva en la Costa Atlántica de Nicaragua, en la Región Autónoma del Atlántico Sur (RAAS). La mayor parte habita en el municipio de Bluefields y una población minoritaria se encuentra en el municipio de San Juan de Nicaragua, en el departamento de Río San Juan. Los ramas son el pueblo indígena de menor población del país, integrado por cerca de 1.600 habitantes.

En la comunidad rama existen artesanos que elaboran bancos, butacas y marcos de cama, para los cuales utilizan madera conocida como banak, nancitón, saba, sambogum y santa maría. La mayoría de los utensilios del hogar son fabricados aún con materiales de plantas como ebo y rosewood. Algunos artículos elaborados con estas maderas son: morteros y mazos, usados para moler granos, kiskis (tenaza), jarros tradicionales, palo para batir guabul, pocillo de madera, pilón para pilar arroz, bote de canalete, canalete, arpón para la captura del snok. Todo construido con materiales procedentes de su entorno, sin perder el respeto por la naturaleza.

\section{Importancia del arco y la flecha en la identidad, la cultura y el turismo}

Históricamente, estos dos instrumentos han sido vitales para la ejecución de actividades relacionadas con caza, pesca y recreación, así como para su propia protección. Con esta recopilación oral del arco y la flecha esperamos apoyar a la comunidad rama, con información disponible para planificar la producción del arco y la flecha como parte de su desarrollo económico, cultural y recreativo. Pero principalmente, a los comunitarios que elaboran esta artesanía, a quienes se dedican a la producción de la materia prima que se utiliza para su producción, aquellos que la utilizan para pescar y cazar, a los que promueven los eventos deportivos y recreativos de arco y flecha, y los que consiguen ingresos en estos eventos: transportistas, comerciantes, promotores, etcétera.

También queremos incidir en el reconocimiento del arco y la flecha utilizados por los ramas, como un elemento cultural sujeto a la salvaguarda del patrimonio cultural inmaterial de la humanidad, pues cumple con los cinco criterios exigidos por la UNESCO para optar a esa condición cultural: valor en tanto testimonio del genio creador humano, arraigo en las tradiciones culturales y sociales, técnicas artesanales tradicionales de aplicación y transmisión, carácter representativo de una comunidad o un grupo determinados y riesgo de su desaparición.

Entre los tipos de artesanía que existen, el arco y la flecha traspasa el criterio de "artesanía utilitaria": hecha para su uso cotidiano (cuchara, tenedor, vasija, arma, etcétera), y se enmarca también en el "estético", como una artesanía de belleza, para admiración de turistas y coleccionistas de artesanías "estéticas" con uso ancestral utilitario.

\section{Materiales e instrumentos para la elaboración del arco y la flecha}

Según las entrevistas y el consenso en los grupos focales, el bambú y el pejibaye son los materiales más usados por los comunitarios para la elaboración de los arcos y flechas, abundantes en todo el trópico húmedo del Caribe, y también usan con menos frecuencia maderas valiosas como el palo de rosa.

\section{Técnicas empleadas para la elaboración del arco y la flecha}

La técnica empleada por los artesanos del pueblo rama para la producción de arcos y flechas, según las comunidades encuestadas, es el corte y secado de la madera a utilizar. La tensada del arco y darle la forma encorvada se consigue con 


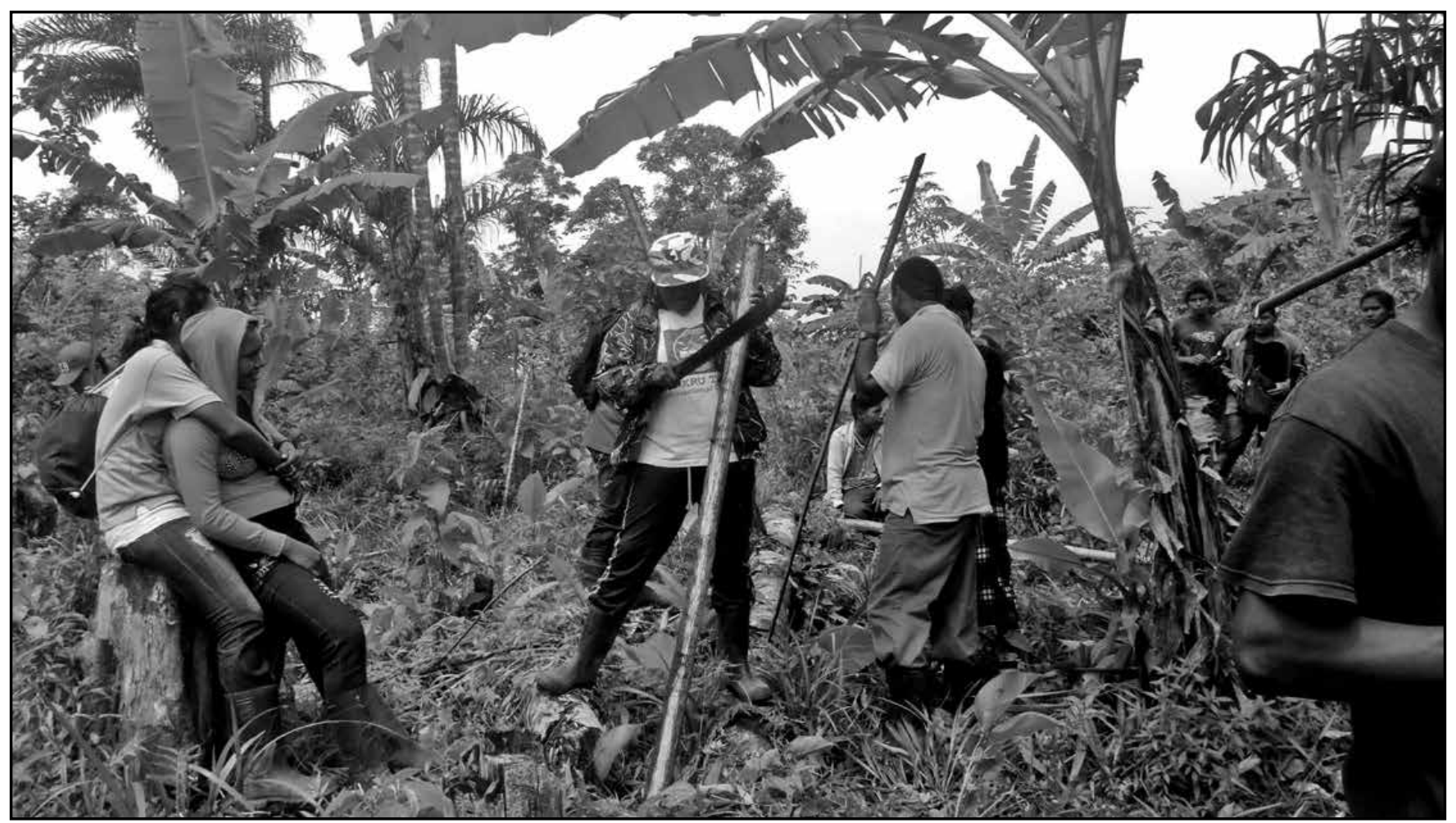

Indígenas ramas preparando varas de las maderas que usan para la elaboración de arcos y flechas.

fibra vegetal o mecate de nilón. En el corte y preparación de las flechas se utiliza la rama de los árboles, el bambú o la caña común. Para su dirección y puntería se incorporan plumas de aves al diseño de la flecha, en su extremo posterior, para su desplazamiento o vuelo. En el otro extremo - la punta de la flecha- se utiliza piedras, metales y maderas afiladas.

\section{El diseño de un arco}

Para construir de manera tradicional un arco rama, el primer paso es buscar una buena vara de grueso adecuado, que mida entre 1,2 y $1,7 \mathrm{~m}$ de largo, lo más regular posible su grosor a todo lo largo. En los extremos se hace una hendidura donde se enganchará la cuerda que tensará el arco. Si se quiere mejorar su aspecto se disminuye, con un cuchillo, sierra o lija, toda la curvatura interna del arco, hasta que queda plana en toda su longitud. La parte exterior del arco, la que queda frente al objetivo, se mantendrá redondeada.

Los ramas fabrican de bejuco resistente la cuerda para tensar el arco, no demasiado gruesa. En la actualidad se utiliza hasta cordón de zapatos. La longitud de la cuerda debe ser la misma que existe entre los dos extremos del arco tensado. La distancia entre la madera del arco y la cuerda tensada no debe exceder a los $20 \mathrm{~cm}$, del centro del arco al centro de la cuerda tensada. En un extremo se ata la cuerda con un nudo fijo, y en el otro se hace un lazo socado y seguro que se puede desenganchar, mientras el arco no esté en uso.

\section{La elaboración de flechas}

Para la elaboración de las flechas se utilizan ramas lo más derechas o rectas posible. La caña salvaje o la caña de bambú, secadas y envejecidas, son de las mejores materias primas para hacer flechas. La longitud de éstas debe ser mayor que la distancia de nuestro mentón a la punta de nuestra mano con el brazo estirado.

Para las puntas de las flechas, el material que se emplea es piedra, hueso, un trozo afilado de metal, clavos, o simplemente madera afilada. En la parte posterior de la flecha se hace una hendidura con un cuchillo o, mejor y más fácil, con una sierra. Esto con el objetivo de colocar allí el timón de la flecha. Para esto se utilizan plumas o cartón. Es necesario evitar utilizar como timón cualquier objeto de material duro, pues puede herir la mano al disparar.

Las plumas ideales utilizadas son las de pavón. Son lo suficientemente duras para soportar el rigor de muchos disparos de la flecha sin deteriorarse. Para el emplumado derecho se debe utilizar plumas del ala derecha del ave, y para emplumado izquierdo, plumas del ala izquierda. 


\section{Herramientas para la elaboración del arco y la flecha}

Para trabajar la madera o darle forma a la rama con que se construye la flecha, se requiere de un machete o serrucho. Con un cuchillo se raspa la pieza, mientras que con la escofina, o con una sierra sinfín, lija o lijadora se desbasta la parte interna para darle la forma de arco; el formón contribuye a lograr este detalle, pero también sirve para hacer el calado en las puntas del arco para amarrar la cuerda que tensa. Asi mismo, cuando se instalan las plumas en la flecha, el esmeril y la lima sirven para afilar las puntas de la flecha.

\section{Etapas y tiempo promedio para la producción de un arco con su flecha}

En la etapa 1se identifica la matera a utilizar. Esto toma un día. Luego sigue el tallado de la madera, lo que puede tomar de tres a sesenta días si hay que secar la madera; el proceso de pulimiento y tensado del arco toma dos días aproximadamente. La preparación del tubo de flecha podrá tomar de uno a diecisiete días si hay que secar el material; la preparación de la punta de la flecha, lo cual consiste en la selección y preparación del material puede tomar dos días y uno más para el retoque final. Un total de 17 a 80 días.

\section{EI arco y la flecha como recreación artística}

El pueblo rama ha manifestado que el arco y la flecha no han sido utilizados únicamente para la caza y la pesca, sino que también han formado parte de la recreación en los tiempos libres. En la comunidad rama se desarrollan concursos de disparos de flechas a distancias determinadas. Usan como blanco, objetos, animales, aves y materiales en puntos fijo; estas gestas, anteriormente se practicaban regularmente entre hombres jóvenes y les servían para afinar puntería.

En la actualidad estos concursos han venido desapareciendo por falta de políticas y programas que tomen en consideración la revitalización de estas prácticas culturales. También falta definir las normas y técnicas de elaboración, construcción, utilización y manejo del arco y la flecha, también como concurso deportivo. Esta actividad tiene las cualidades de un arte cultural, puede servir como entretenimiento comunal y turístico y funcionar como un generador de ingreso para el pueblo rama (venta de pequeñas flechas, tiro al blanco, etcétera).

\section{Propuesta para la revitalización y transmisión de la artesanía del arco y la flecha}

* Elaborar y poner en funcionamiento un plan que cuente con el concurso de los diferentes gobiernos (nacional, regional, municipal, comunal y territorial) que contenga los elementos de rescate, transmisión y promoción del arco y la flecha, como un instrumento deportivo recreativo de la cultura rama.

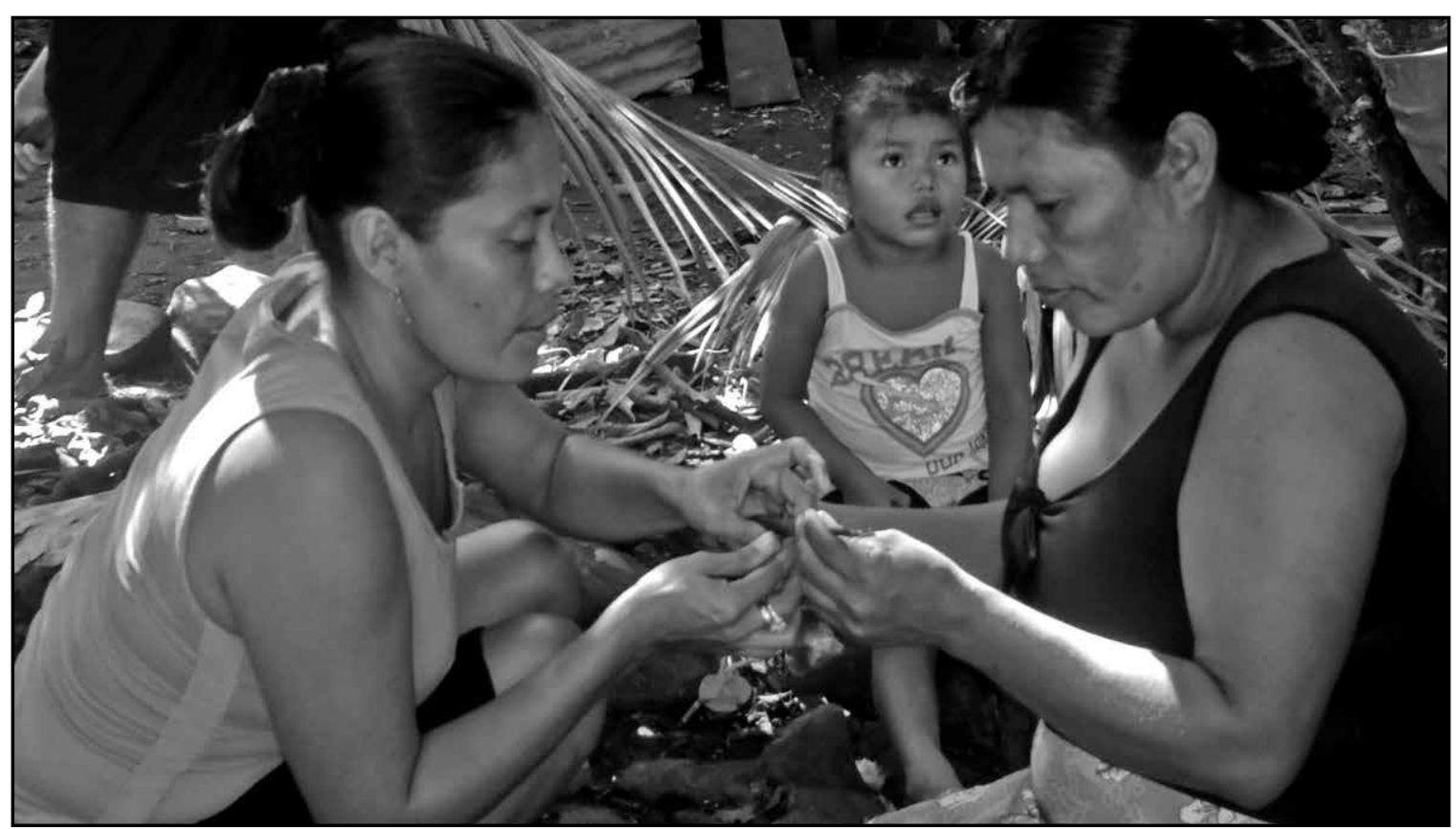

Urge un plan de revitalización del arco y la flecha de la nación rama. 
* Que esta investigación dé como resultado el involucramiento de centros de investigación, universidades e investigadores, interesados en este plan de revitalización.

* Hacer una revisión de las leyes y normas nacionales y regionales que regulan el uso de instrumentos que pueden considerarse como prohibida (arco y flecha) su utilización en lugares y para actividades determinadas.

* Apoyar la creación de una base de datos donde sean incorporadas las prácticas artesanales y culturales de estos pueblos caribeños, en donde el arco y la flecha sean partes de este registro.

* Incorporar en los pensum educativos de las universidades y centros tecnológicos, cursos, diplomados y estudios técnicos de diseño, con la participación de jóvenes de la etnia rama y de las comunidades que tiene vocación para ser diseñadores.

\section{Conclusión}

Esta investigación contribuyo a identificar, junto con el pueblo rama, la necesidad de una intervención para el rescate, documentación y transmisión de los conocimientos teóricos y prácticos, de la construcción y utilización del arco y la flecha como una herramienta de artesanía tradicional de identidad cultural del pueblo rama. Así mismo contribuyo a seleccionar los mecanismos de intervención para iniciar la transmisión y documentación del conocimiento oral del arco y la flecha, como una artesanía del pueblo rama.

El nivel de riesgo de desaparición de este arte se puede valorar como alto, debido a que esta práctica no se encuentra documentada; por otro lado, los maestros portadores son personas con edades que oscilan entre los 60 y 80 años.

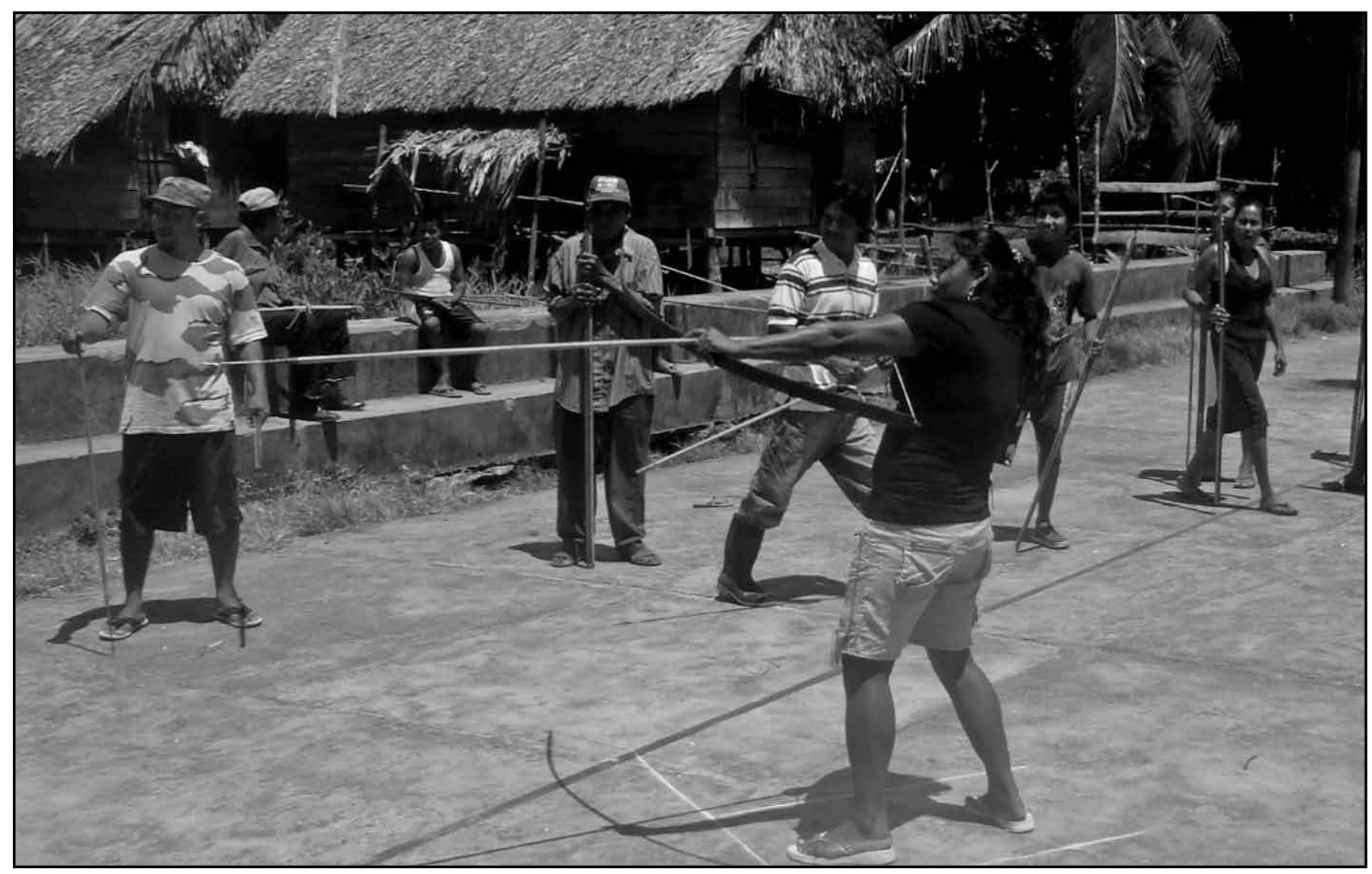

Concurso de puntería con arco y flecha en Karawala. 